the individual industries that have any executive authority. It was decided, as a first step, that the Council should seek factual information from the industries as to their future needs and opportunities for training personnel. The Council agreed that industries should first be encouraged to undertake the assessments--suggested by the Carr Committeeas to their future man-power needs and to compare these with existing facilities for training. It was stressed in particular that there is an urgent need for each industry to make some quantitative assessment to satisfy itself that its training arrangements will be adequate to meet the coming 'bulge' in school leavers. The Council further decided to ask each industry to state in general terms how far, if at all, it has dealt with the main recommendations in the report of the Carr Committee which cover the whole field of training of young workers.

\section{Graduate Training in Chemical Engineering}

IT has been realized for many years that a student who has obtained a degree in engineering at a university is by no means fully equipped to take his place in an industrial concern, and many large firms have organized training courses of a practical nature which supplement the fundamental and more theoretical knowledge acquired at the university. In chemical engineering, owing to the diversity of subjects dealt with, it is not easy to decide the exact form which such courses should take, and in view of the increasing demand for guidance in this matter, the Education Committee of the Institution of Chemical Engineers, after consultation with the Association of British Chemical Manufacturers and the British Chemical Plant Manufacturers Association, has now published a brief advisory note. In this it is pointed out that it seems desirable for every chemical engineering graduate to have practical training in four main subjects - the design, fabrication, development and operation of process plant. Two years is suggested as the total period of training, but the time allocated to each subject should vary substantially according to the type of work which the trainee is intended to take up. During the training it should be possible to emphasize such subjects as costing, labour management, safety and report writing. A schedule in somewhat greater detail is given. Twentyseven large organizations are at present operating training schemes which conform with these suggestions and the note should prove very helpful as a guide to firms which are contemplating the introduction of organized postgraduate training into their business.

\section{Building Research}

THE latest reports of the Building Research Board and of the Director of Building Research of the Department of Scientific and Industrial Research have been published in a booklet entitled "Building Research 1957" (pp. iv $+75+16$ plates. London: H.M. Stationery Office, 1958. 5s. 6d. net). These reports are of special topical interest following the recent criticism of the annual report of the Building Research Station by the Select Committee on Estimates in the course of its inquiry into the finances of the Station; the Committee complained that the report was of too general a nature to be of much value to those interested in the work of the Station. Opinions will, no doubt, differ on this point, but all familiar with the building industry will appreciate the difficulties facing the Director in compiling his report.
In order that the Building Research Station should be in a position to view all building problems in their correct perspective, the programme of work undertaken is very broad, ranging from rheology to the packaging of bricks. The Station is, nevertheless, able to make a number of contributions to basic research in several fields. For example, the high. temperature microscope, described in the report for 1956, has been further developed and a new instrument has been constructed which permits observations to be made in special atmospheres at temperatures exceeding $2,000^{\circ} \mathrm{C}$. Further contributions have arisen out of the Station's work on lighting and heating, and an investigation of the aircraft-noise nuisanee problem has given rise to some basic research on sound propagation in the open air.

\section{Cancer and Mental Hea'th in 1952-53}

THE Registrar General has recently issued two supplements to his Statistical Review (Supplement on Mental Health for 1952-3. Pp. xi+208. 11s. $6 d$. Supplement on Cancer for 1953. Pp. xi +105. 7s. 6d. London: H.M. Stationery Office, 1958). The cancer volume is a continuation of previous studies, dis. cussing figures obtained from the cancer registration scheme for eight further sites : in women, the corpus uteri and ovary; in men, the testis and penis ; and in both sexes, lip, tongue, mouth and pharynx, and the osophagus. New registration-rates and mortalityrates are presented for each site, and there are figures showing mortality in each year of treatment and the five-year survival-rate in relation to the clinical state of the disease at registration and by method of treatment, and there is a text section commenting briefly on the principal results.

The supplement on mental health is more comprehensive. It gives figures relating to the population of patients in mental hospitals and mental deficiency hospitals, the duration of stay and the incidence of mental disease, as measured by new registrations, among different groups of the population. The figures are divided by age, marital status and occupation. The period considered is too short for significant trends to emerge, but it might be noted that between 1950 and 1953 the median duration of stay for patients discharged from mental hospitals steadily decreased. The incidence of mental disease is particularly high among the single, and in Group V, the lowest group of the Registrar General's classification. Adverse rates of mental disease also seem to be connected with a high standard of education, clerical and domestic work, labouring and branches of the catering industry, but the Registrar General recognizes that in this field it is difficult to disentangle cause and effect and that further ecological studies are required.

\section{The Neolithic Age in Eastern Siberia}

THE new volume of the Transactions of the American Philosophical Society (New Series, 48, Part 2 (1958): "The Neolithic Age in Eastern Siberia". By Henry N. Michael. Pp. 108. Philadelphia : American Philosophical Society, 1958. 2.50 dollars) will be much welcomed by prehistorians. Here in the West it is not too easy to obtain accounts of investigations made in Siberia, especially as many of the articles are written in Russian. Some little while ago there was a short article on "Eskimo Archæology" by H. B. Collins which appeared in the Proceedings of the American Philosophical Society. But this only touched on some of the early stone age finds near Lake Baikal and 